\title{
Antidepressant Prescriptions in Neurosurgical Practice: A Survey of Current Trends
}

\author{
Ahmed B. BAYOUMI' ${ }^{1}$ Ibrahim E. EFE ${ }^{1,2}$, Ozden Caglar OZTURK ${ }^{1}$, Burhan YOKUS ${ }^{1}$, Ayse UZUNER ${ }^{3}$, \\ Turker KILIC ${ }^{1}$, Selma BOZKURT ${ }^{4}$, Zafer Orkun TOKTAS ${ }^{1}$ \\ ${ }^{1}$ Bahcesehir University School of Medicine, Medical Park Goztepe Hospital, Department of Neurosurgery, Istanbul, Turkey \\ ${ }^{2}$ Charite Universitätsmedizin, Department of Neurosurgery, Berlin, Germany \\ ${ }^{3}$ Marmara University, Faculty of Medicine, Istanbul, Turkey \\ ${ }^{4}$ Bahcesehir University School of Medicine, Medical Park Goztepe Hospital, Department of Psychiatry, Istanbul, Turkey
}

Corresponding author: Ahmed B. BAYOUMI abayoumigcsrt@gmail.com

\section{ABSTRACT}

AIM: To better understand the indications and the impact of antidepressant drugs on the field of neurosurgery in terms of risks and benefits in Turkey.

MATERIAL and METHODS: A national survey was conducted among neurosurgeons in current practice in Turkey to report routine prescription trends of antidepressant drugs. Gender, neurosurgical subspecialty, city, type of practice, years of experience, antidepressant agent, indications and reasons not to prescribe were ascertained. A brief review of literature was done to show clinical and research evidence.

RESULTS: A total of 336 neurosurgeons took the survey; $53 \%$ of them prescribe antidepressants routinely, whereas $47 \%$ of them do not. Of the $72 \%$ non-prescribers prefer to refer their patients to a psychiatrist and $22 \%$ of them believe that antidepressants have no role in neurosurgery. Vascular and pediatric neurosurgeons as well as neurosurgeons at research hospitals showed the lowest prescription proportion, while general and brain tumor neurosurgeons and ones in private practice showed the highest prescription proportion. Surgeons with more than 20 year-experience had the lowest prescription proportion (43\%). Type of practice and years of experience showed a statistically significant association with the prescription of antidepressant drugs across $(p=0.002$ and $p=0.025$, respectively).

CONCLUSION: Type of practice and years of experience showed a statistically significant association with the proportion of antidepressants' prescribers in Turkish neurosurgery practice at the time of this survey. Non-prescriber neurosurgeons need to recognize the indications, whereas prescribers have to understand the risks of using antidepressants.

KEYWORDS: Survey, Neurosurgery, Antidepressants, Antidepressant Drugs, Turkey

\section{INTRODUCTION}

A ntidepressants represent a major group of drugs in Central Nervous System (CNS) pharmacotherapy. Despite being widely used to treat different types of psychiatric illnesses including major depressive disorder, panic disorder, types of phobias, obsessive compulsive disorders, eating disorders and sleep disorders, it can be used to treat non-psychiatric conditions including neuropathic pain, premature ejaculation and nocturnal enuresis. The benefits and hazards of using antidepressants in the context of neurosurgery practice have been frequently reported in the literature $(7,13,28,30)$.

In spine degenerative diseases, antidepressants can be useful in the treatment of neuropathic pain induced by root compres-
Ahmed B. BAYOUMI (10): 0000-0003-4548-3037

Ibrahim E. EFE (1D): 0000-0002-4232-3305

Ozden Caglar OZTURK (10): 0000-0003-3964-1895
Burhan YOKUS (D) : 0000-0001-7050-2290

Ayse UZUNER (D): 0000-0002-6471-7452

Turker KILIC (D) :0000-0002-9396-628X
Selma BOZKURT (D) : 0000-0001-8210-5524 Zafer Orkun TOKTAS (D) : 0000-0002-5842-5891 
sion, but can harbor the risk of increasing the incidence of intraoperative bleeding in lumbar surgeries $(7,32,35,36)$. Antidepressants' utility to treat coexisting psychiatric illnesses such as perioperative anxiety or depression in patients with terminal brain malignancy should be considered. Moreover, several experimental preclinical laboratory research studies demonstrated the possible proapoptotic effect of antidepressants on glioma and neuroblastoma cell lines suggesting its promising therapeutic effect in killing cancer cells that may simulate that of temozolomide $(10,11,14,38)$. However, there is clear variation in each neurosurgeon's practice based on his/her experience and theoretical knowledge regarding the indications of antidepressants. Furthermore, the necessity to consult a qualified psychiatrist in each condition may be controversial.

To the best of our knowledge while conducting this study, there is no published report on the neurosurgeons' prescription patterns as they relate to antidepressants in their routine clinical practice. The aim of our study is to ascertain common trends in neurosurgery practice among different classes of neurosurgeons who may vary in their areas of subspecialty, years of experience, location or type of practice. We also provide a brief evidence-based overview of the literature on the risks and benefits of antidepressants in neurosurgery, and highlight new research advancements from both the neurosurgical and psychiatric perspectives.

\section{MATERIALS and METHODS}

This study (survey) is exempt from our Institutional Review Board (IRB of Bahcesehir University) being one of the 6 exempt categories that do not require research ethical approval or continuous monitoring. No patients' records or data from minors or prisoners were used in this project. A verbal consent was taken from each surgeon without a necessity to declare his/her identity before filling the questionnaire.

This is a cross-sectional study conveyed by a short survey consisting of 9 major questions (Figure 1) which was manually delivered at 3 conference meetings: Turkish Neurosurgical Meeting, International Turkish Spine Congress, World Federation of Neurosurgical Societies, that took place in Turkey in 2017. Only neurosurgeons with a current active practice in Turkey were considered for the survey. Convenience sampling was the technique employed to reach the highest number of neurosurgeons. The sample size needed to represent the Turkish Neurosurgical Community (about 1500 neurosurgeons) was calculated to be 306 with a confidence level of $95 \%$ and confidence interval of 5 .

The survey covered gender, city, subspecialty, type of practice, years of experience, and specific questions about antidepressants prescriptions in terms of indications, types, drugs and reason for not prescribing antidepressants.

Based on the results of our survey, we felt it is pertinent to supplement our work with a brief narrative review of the literature to provide neurosurgeons with an overview of antidepressants in terms of relevant indications, hazards and new research advances from both the neurosurgical and psychiatric perspectives. The review is focused on the impact of antidepressants on the neurosurgical spectrum of diseases and coexisting psychiatric illnesses that may frequently be seen by neurosurgeons in the inpatient and outpatient settings.

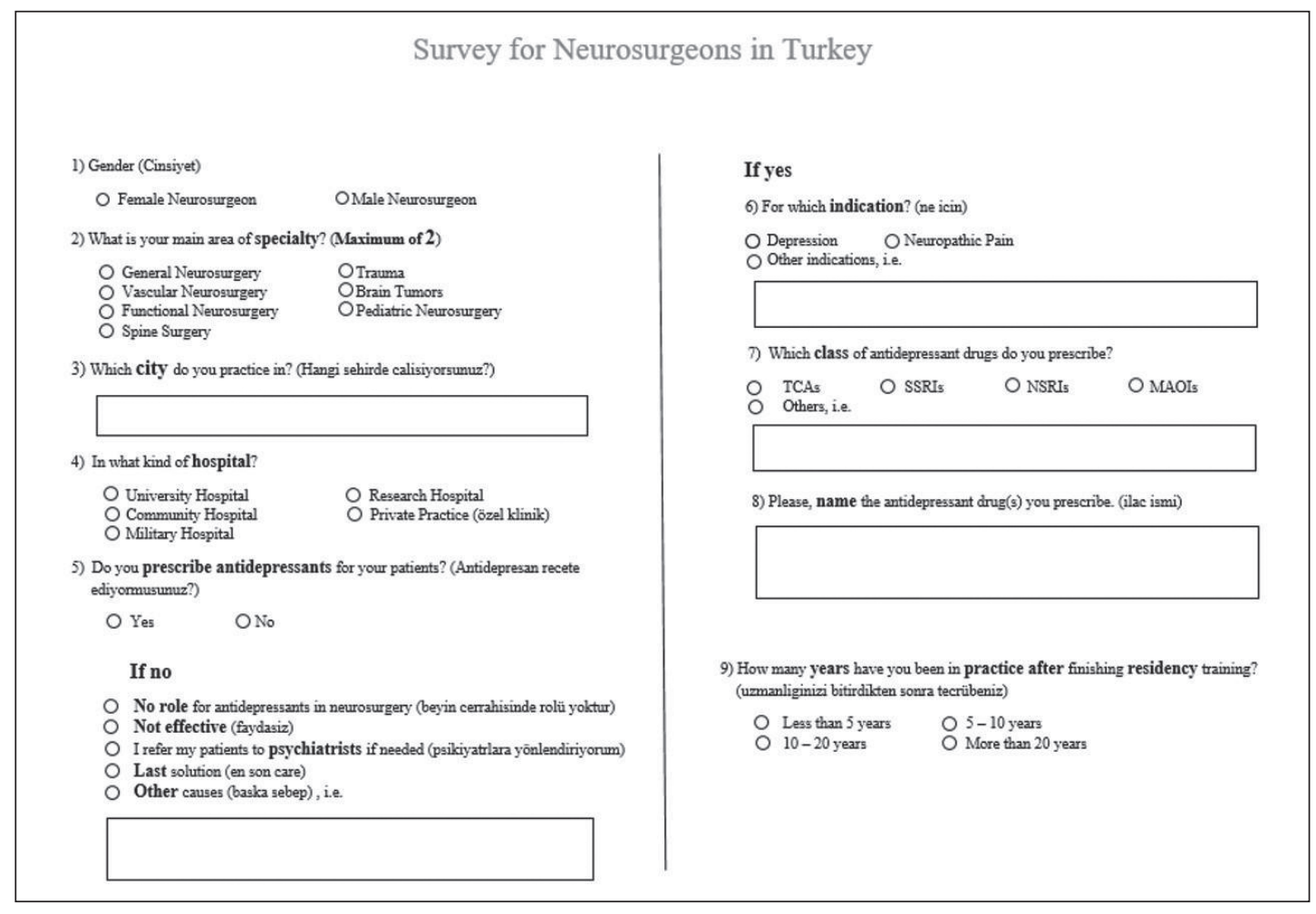

Figure 1: Survey used to explore the current trends of antidepressants prescription in neurosurgery practice in Turkey. 
Data analysis was performed using IBM SPSS Statistics version 17.0 software (IBM Corporation, Armonk, NY, USA). Descriptive statistics for categorical data were expressed as number of participants and percentages. The ContinuityCorrected Chi-square test was used when one or more of the cells had an expected frequency of 5-25 to compare categorical variables in the $2 \times 2$ contingency tables, otherwise, the Pearson's Chi-square test was performed. Additionally, in the $\mathrm{R} \times \mathrm{C}$ contingency tables, categorical data were also analyzed by Pearson's Chi-square test. A $p$ value less than 0.05 was considered statistically significant.

\section{RESULTS}

Three hundred thirty-six neurosurgeons actively practicing in Turkey responded to our survey. This included 28 female participants (8.3\%) and 308 male participants (91.7\%) (Table l).

Over half of the interviewed surgeons practiced in the three major cities of Istanbul (37.9\%), Ankara (8.93\%) and Izmir (8.63\%). Regarding years of practice, 113 (33.6\%) participants had less than 5 years, $87(25.9 \%)$ had 5 - 10 years, $85(25.3 \%)$ had 11 - 20 years and 51 (15.2\%) had more than 20 years of experience. The most common subspecialty was general neurosurgery $(46.7 \%)$, followed by spine surgery $(36 \%)$, and brain tumors (20.8\%). Among the 336 surgeons, 151 (44.9\%) were affiliated with university hospitals, $31.8 \%$ with research hospitals, $8.3 \%$ with community hospitals, and $14.9 \%$ worked in private practice.

Table I: Demographic Profile of Survey Participants

\begin{tabular}{lc}
\hline Characteristic & $\begin{array}{c}\text { Number of Participants } \\
\mathbf{n}=336\end{array}$ \\
\hline Gender & $28(8.3 \%)$ \\
Female & $308(91.7 \%)$ \\
Male & \\
\hline Years of Experience & $113(33.6 \%)$ \\
$<5$ years & $87(25.9 \%)$ \\
$5-10$ years & $85(25.3 \%)$ \\
$11-20$ years & $51(15.2 \%)$ \\
$>20$ years & \\
\hline Main Specialty & $157(46.7 \%)$ \\
General & $38(11.3 \%)$ \\
Trauma & $47(14.0 \%)$ \\
Vascular & $70(20.8 \%)$ \\
Brain Tumors & $24(7.1 \%)$ \\
Functional & $28(8.3 \%)$ \\
Pediatric & $121(36.0 \%)$ \\
Spine &
\end{tabular}

One hundred seventy-eight participants (53\%) routinely prescribed antidepressants, while 158 (47\%) did not. When asked for reasons not to prescribe, $72.2 \%$ answered that they would refer their patients to a psychiatrist. Interestingly, 35 neurosurgeons $(22.2 \%)$ believed that antidepressants had no role in neurosurgical practice. Among prescribers, 75.3\% considered antidepressant treatment for neuropathic pain, and $66.3 \%$ for depression. The most frequently chosen drug classes were selective serotonin reuptake inhibitors (SSRI; $79.8 \%$ ) and tricyclic antidepressants (TCA; 30.3\%). Sertraline (36\%), amitriptyline (24\%), and escitalopram (19\%) were the most popular drugs (Table II).

Table III demonstrates work experience and type of practice in association with prescription habits. Chi-square analysis showed significantly lower prescription rates in participants with less than 5 years of experience compared to those with $5-10$ years of experience $(p=0.025)$, and $11-20$ years of experience $(p=0.016)$. Interestingly, prescription of antidepressants is lower in the group with over 20 year-experience compared to the group with $11-20$ years of practice $(p=0.045)$ (Figure 2). Prescription rate was higher in the private practice setting

Table II: Frequency of Answers to Survey Questions "5" to "8"

\begin{tabular}{ll}
\hline Question & $\mathbf{n}(\%)$ \\
\hline Do you prescribe antidepressants? & \\
Yes & $178(53.0)$ \\
No & $158(47.0)$
\end{tabular}

Reasons Not to Prescribe

Referring to Psychiatrists $114(72.2)$

No Role

$35(22.2)$

As Last Solution $8(5.1)$

Not Effective $\quad 7$ (4.4)

Other $3(1.9)$

$\begin{array}{lr}\text { Indications for Prescription } & \\ \text { Neuropathic Pain } & 134(75.3) \\ \text { Depression } & 118(66.3) \\ \text { Other } & 24(13.5)\end{array}$

Preferred Drug Class

SSRI $\quad 142(79.8)$

TCA 54 (30.3)

SNRI $34(19.1)$

MAOI 4 (2.2)

Other 7 (3.9)

$\begin{array}{lc}\text { Preferred Drug } & \\ \text { Sertraline } & 64(36.0) \\ \text { Amitryptiline } & 42(23.6) \\ \text { Escitalopram } & 34(19.1) \\ \text { Citalopram } & 27(15.2) \\ \text { Venlafaxine } & 16(9.0) \\ \text { Duloxetine } & 14(7.9) \\ \text { Fluoxetine } & 6(3.4) \\ \text { Paroxetine } & 3(1.7) \\ \text { Mianserine } & 1(0.6) \\ \text { Other } & 1(0.6)\end{array}$


Table III: Association of Demographic Characteristics and Prescription Rate

\begin{tabular}{lrc}
\hline & Prescribers & $\mathbf{p}$ \\
\hline $\begin{array}{l}\text { Gender } \\
\text { Female }\end{array}$ & \\
Male & $12(42.9 \%)$ & \\
\hline Years of Experience & $166(53.9 \%)$ & $0.356^{\dagger}$ \\
$<5$ years & & \\
$5-10$ years & $51(45.1 \%)$ & \\
$11-20$ years & $52(59.8 \%)$ & $0.025^{\ddagger}$ \\
$>20$ years & $53(62.4 \%)$ & \\
\hline
\end{tabular}

\section{Affiliation}

University Hospital

$77(51.0 \%)$

Research Hospital

$46(43.0 \%)$

$0.002^{\ddagger}$

Community Hospital

$18(64.3 \%)$

Private Practice

$37(74.0 \%)$

† Continuity corrected Chi-square test, $¥$ Pearson's Chi-square test.

Table IV: Association of Neurosurgical Subspecialty and Prescription Rate

\begin{tabular}{lcc}
\hline & Prescribers/Total (\%) & p \\
\hline General Neurosurgery & $91 / 157(58.0 \%)$ & $0.086^{\dagger}$ \\
\hline Trauma & $20 / 38(52.6 \%)$ & $>0.999^{\ddagger}$ \\
\hline Vascular & $17 / 47(36.2 \%)$ & $\mathbf{0 . 0 2 0}^{\ddagger}$ \\
\hline Brain Tumors & $39 / 70(55.7 \%)$ & $0.606^{\dagger}$ \\
\hline Functional & $12 / 24(50.0 \%)$ & $0.928^{\ddagger}$ \\
\hline Pediatric & $13 / 28(46.4 \%)$ & $0.598^{\ddagger}$ \\
\hline Spine & $65 / 121(53.7 \%)$ & $0.838^{\dagger}$ \\
\hline
\end{tabular}

† Pearson's Chi-square test, $¥$ Continuity corrected Chi-square test.

than in university hospitals $(p=0.007)$ and research hospitals $(p<0.01)$ (Figure 3).

The greatest number of prescribers were found among general neurosurgeons $(58 \%)$, and brain tumor surgeons $(55.7 \%)$. In contrast, vascular neurosurgeons reported a significantly lower rate of prescription $(\mathrm{p}=0.02)$ (Figure 4 , Table IV).

\section{DISCUSSION}

The role of antidepressants in neurosurgery is not wellunderstood by a large portion of neurosurgeons seeing as they tend to overlap with psychiatric indications. We could not find a previously published survey conducted by any national or international neurosurgical community that examined the trends of prescriptions among neurosurgeons to compare our survey's results to.

Of note, neurosurgeons from cities with the highestpopulations in Turkey, such as Istanbul, Ankara and Izmir, prescribe antidepressant drugs less than their colleagues

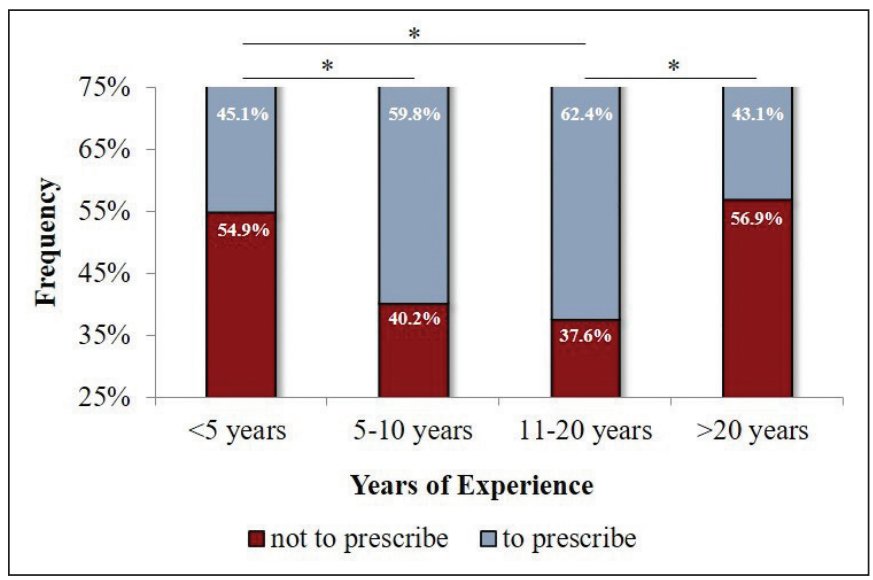

Figure 2: Graph showing the proportion of antidepressant prescription based on years of experience (*: p-value $<0.05)$.

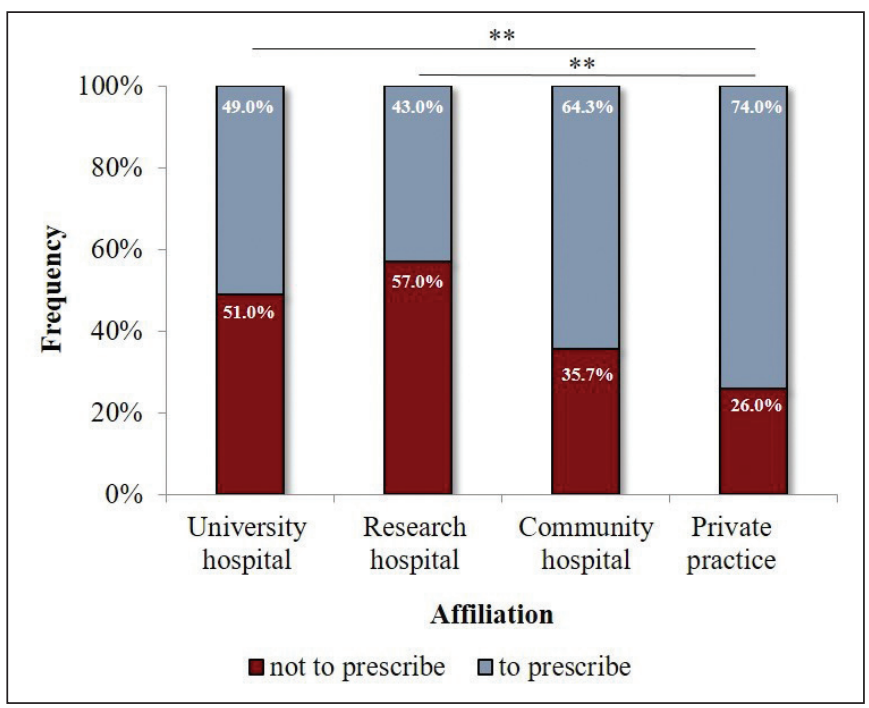

Figure 3: Graph showing the proportion of antidepressant prescription based on type of neurosurgery practice ${ }^{* *}$ : $p$-value $<0.01)$.

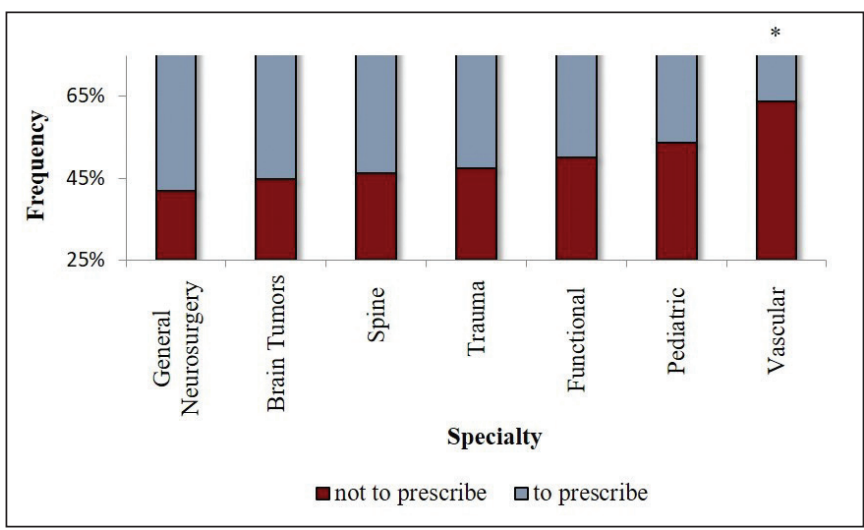

Figure 4: Graph showing the proportion of antidepressant prescription based on subspecialty in neurosurgery $(*$ : $p$-value $<0.05)$. 
in lower-population cities (42\% versus 60\%). Moreover, neurosurgeons in west coast cities prescribed less than those in the eastern cities of Turkey ( $43 \%$ versus $59 \%$ ). This can be explained by the comparatively better economic status of western cities in terms of the availability of psychiatrists to whom patients can be referred. Furthermore, neurosurgeons who worked at research medical centers and university hospitals (i.e. tertiary Medical Centers) had a significantly less prescription rate than those who worked in private practice or community public hospitals. This can be explained by the fact that in an academic setting, neurosurgeons are supported by psychiatry consultants who can aid in the management of patients with coexisting psychiatric disorders.

It is logical that a low rate of antidepressant prescription was observed among pediatric neurosurgeons. This can be attributed to the nature of diseases encountered. However, pediatric brain tumors are not uncommon and diagnosis of a concurrent psychiatric illness in this group of patients can prove to be more challenging; requiring referral to a pediatric psychiatrist. Vascular neurosurgeons also showed a low antidepressant prescription rate which may go hand in hand with the higher risk of developing intracranial hemorrhage as reported in the literature (31). Brain tumor surgeons' prescription rate was relatively high (55.7\%), likely due to the high volume of malignant tumors they treat, such as brain metastases and high-grade gliomas, which may prompt prescription of such antidepressant agents more frequently.

Years of experience showed that neurosurgeons with over 20 years of experience were less likely to prescribe antidepressant agents (43.1\%). We believe that continuous medical education can help to raise awareness in this area despite their long experience in the field. Furthermore, surgeons with less than 5 years of experience may feel hesitant to prescribe antidepressant agents (45.1\%) due to their lack of knowledge early in their career.

The main limitation of this survey was the relatively low percentage of participants (about 22.4\%) in a relatively small population (i.e. 1500 neurosurgeons) which may not represent the entire neurosurgical community in Turkey. Moreover, the convenient sampling technique in conference meetings may not be quite representative, but we can argue that such meetings provide us with a reasonable distribution of neurosurgeons to represent different cities. The potential pitfalls may include the language barrier. We, however, tried to use both English and Turkish in our survey. We also used few open ended questions and allowed the participants to pick more than one choice. Therefore, general neurosurgery, being a common subspecialty, had the highest prescription rate of antidepressants.

Our survey demonstrated that the neurosurgery community in Turkey is divided when it comes to routine prescription of antidepressants $47 \%$ who did not versus $53 \%$ who did. Therefore, we felt the necessity to review the current literature to demonstrate the risks and benefits of this group of drugs in the field of neurosurgery from both the neurosurgical and psychiatric perspectives.

\section{A Brief Narrative Review of Literature}

\section{a) Treatment of Neuropathic Pain:}

Tricyclic antidepressants (TCAs) and selective serotonin reuptake inhibitors (SSRIs) have well-established indications in the treatment of conditions characterized by neuropathic pain. Venlafaxine, as a serotonin norepinephrine reuptake inhibitor (SNRI), was shown to be an effective treatment in 9 out of 13 clinical studies examined in a narrative review by Trouvin et al. (39).

In neurosurgery practice, we encounter several conditions with neuropathic pain including trigeminal neuralgia and radiculopathy in the form of brachialgia, femoralgia or sciatica. According to the November 2013 (updated in 2017) UK guidelines, antiepileptics (e.g. Pregabalin, Gabapentin) and antidepressants (e.g. Amitriptyline, Duloxetine) are first class choice pharmacotherapy for peripheral and central neuropathic pain (except trigeminal neuralgia where carbamazepine is preferred). Each of those 4 drugs can be tried alone before switching to one of the other 3 drugs based on patient response and side effects (1).

\section{b) Role in Spine Surgery:}

In addition to the popular indications for TCAs to treat neuropathic pain, related to nerve root impingements in spine degenerative diseases, neurosurgeons need to be aware of the impact of antidepressants on clinical outcomes and intraoperative events. A case-control study published in 2011 reported a statistically significant increase in intraoperative blood loss especially in anterior cervical discectomy and fusion (ACDF), and posterior lumbar fusion surgery. They also showed an increase in hospital stay following elective spine surgeries for patients who received SSRI/SNRIs drugs. They recommended switching patients from serotonergic antidepressants to other drugs that do not inhibit serotonin reuptake (eg. Bupropion) or mildly inhibit serotonin reuptake (eg. Mirtazapine) when significant blood loss is anticipated. A combination of SSRIs with antiplatelet medications should also be limited preoperatively (36). In patients taking SSRI, a platelet function assay before elective surgeries can be considered (21). Movig and his colleagues demonstrated the higher need for perioperative blood transfusion for patients undergoing an orthopedic surgical procedures on SSRIs compared to those on non-serotonergic antidepressants (26).

In patients with coexisting depression and cervical spine pathology, pretreatment of depression for 6 months prior to surgery with antidepressants by a qualified psychiatrist improved patients' perception to pain and functional disability one year following surgery (6). Psychotropic drugs including antidepressants can be quite useful in treating chronic spinal disorders especially when neuropathic pain is involved in the underlying pathology (27).

\section{c) Risk of Intracranial Hemorrhage:}

In a nested case-control study conducted on a large cohort in the United Kingdom, the use of SSRI revealed a higher risk of intracranial hemorrhage, with a relative risk of $(\mathrm{RR}=1.17)$ compared to TCAs during the first 30 days of use. Selective 
serotonin inhibitors also showed a $25 \%$ increase in risk during the first 30 days of use. Concomitant use of oral anticoagulants substantially increased the risk $(R R=1.73)$ but the confidence interval was reported as $(95 \% \mathrm{Cl}=0.89-3.39)$ (31). Another group of researchers found that concomitant use of warfarin together with SSRI/SNRIs served as an independent risk factor for case fatality in primary intracerebral hemorrhage, with an adjusted Hazard Ratio of $2.1(p=0.019)(18)$.

\section{d) Possible Cytotoxic Effect:}

Martinez and colleagues in 2015 showed improved overall survival for patients with brain metastasis with low expression of Kv10.1 potassium channels and antidepressant treatment compared to untreated patients. Their data suggested a potential therapeutic role for TCA in the treatment of brain malignancies (23). Several studies revealed the neuroprotective effect of several antidepressants in enhancing the survival of neural cells by activating the BDNF and NGF (25). Citalopram and Reboxetine showed increased BDNF in rats' hippocampi $(33,34)$. To the contrary, Spanova et al. reported on Fluoxetine-induced apoptosis in C6 rat glioma cells (38). Levkovitz et al. examined the differential effect of antidepressants on apoptosis on glioma and neuroblastoma cell lines finding that paroxetine had lower sensitivity in primary mouse brain and neuronal cultures in terms of its cytotoxic or proapoptotic effect. Flowcytometry and fluorescent microscopic examination demonstrated the apoptotic effect of paroxetine, fluoxetine and clomipramine, while it did not show such effect for the atypical antidepressants, imipramine or mianserine. Although the apoptotic mechanism had not yet been established, they suggested the activation of $p$-cJun and subsequent increased Cytc mitochondrial release to play a role (14). A preclinical study (in vivo) on an animal model conducted by another research group in 2014 found that fluoxetine was bound to AMPAR (a-amino-3-hydroxy5-methyl-4-isoxazolepropionic acid receptor) which could induce $\mathrm{Ca}^{2+}$ influx inside cells to overload the mitochondria and trigger apoptosis, in a similar effect to Temozolomide (17). In a study conducted by Ramezani et al. on human glioblastoma stem-like cells and published in 2017, rolipram potentiated the effect of bevacizumab to kill cells with high expression of $\mathrm{VEGF}_{\mathrm{A}}$ (29). A nationwide study, conducted in Denmark in the form of a case-control study, showed that long-term use of TCAs could be associated with a lower risk of gliomas with an odds ratio $(\mathrm{OR}=0.72)$, but that did not reach statistical significance (28).

\section{e) Psychiatric Indications in a Neurosurgical Setting:}

A substantial number of neurosurgery patients experience various psychiatric symptoms. These symptoms may occur due to head trauma, intracranial tumor, vascular malformation, intracranial hemorrhage, or as a psychological response to a diagnosis or surgical planning (15). Patients may present with vague or mixed typesof neuropsychiatric, cognitive or behavioral manifestations which may overlap with the clinical picture of the space occupying lesion $(19,20)$. They may develop mood symptoms, affective changes, psychosis, memory problems, personality changes, anxiety, or anorexia.
It is well-known that psychological factors may affect surgical outcomes $(3,4,22,24)$. Diagnosis of a psychiatric disorder secondary to a neurosurgical condition is usually based on initial clinical suspicion. Early diagnosis is crucial to start treatment at early stages appropriately and critical to improve patient's quality of life $(15,20,22,24)$. Clinically, depression seems to be associated with worse overall survival in glioma patients $(16,22)$. Depressive symptoms often accompany increased irritability or anxiety. Anxiety may result from situational fear or stress related to diagnosis and/or prognosis or may be directly related to the effects of the tumor $(19,20)$. According to the results of a study on 598 patients with high-grade glioma, depression was reported to be common in the preoperative and postoperative periods, but there was a discrepancy between the physicians and patients' reports regarding depression. In that study, physicians reported depression in $15 \%$ of patients, whereas $93 \%$ of patients reported symptoms consistent with depression (3). Anxiety symptoms may affect length of hospital stay following surgery $(2,5,9,24)$. Despite the significant impact on cost of neurosurgical procedures, there are few studies published regarding the effect of perioperative anxiety on duration of hospitalization in the neurosurgical literature $(8,24)$.

In a study conducted on patients with brain tumors, a substantial proportion of all patients (56\%) had Generalized Anxiety Disorder (GAD) or depression. However, only $44 \%$ of these patients received medications to treat anxiety or depression $(4,19)$. These findings may reflect; (1) failure to accurately diagnose depression or generalized anxiety disorder, (2) hesitance among physicians to treat psychiatric disorders in brain tumor patients, or (3) inadequate assessment of brain tumor patients on follow-up outpatient visits (3). Antidepressant drugs are usually the drug of choice to treat either GAD or depression.

Based on our survey, we found that almost half the respondent $(47 \%)$ did not prescribe antidepressants routinely. $22 \%$ of them believed that antidepressants had no role in neurosurgery practice. It is therefore important that neurosurgeons familiarize themselves with easily-administered psychiatric assessment tools such as the "Beck Depression Scale" and the "Beck Anxiety Scale" $(12,37)$. Such helpful tools can allow them to better diagnose psychiatric disorders and may significantly affect outcomes and overall quality of life of their patients. A score of less than 17 represents minimal or mild symptoms that do not necessarily require psychiatric consultation, but it is recommended to get a psychiatrist involved in the management of cases with moderate or severe symptoms (i.e. a score higher than 16 on scale).

\section{- CONCLUSION}

Type of practice and years of experience are associated with a higher proportion of antidepressant prescribers among neurosurgeons in Turkey, at the time of our survey. Whereas "non-prescriber" neurosurgeons have to recognize the indications of antidepressants for neurosurgical conditions and coexisting psychiatric disorders, "prescriber" neurosurgeons need to be aware of hazards of antidepressants 
in a neurosurgical setting. We need to raise the awareness of neurosurgeons concerning the use of antidepressant drugs in the field of neurosurgery in terms of benefits and risks.

\section{ACKNOWLEDGMENT}

We would like to acknowledge Dr. Snezana Konjikusic for her contribution to statistical analysis and Orhun U. Aydin for his help at the WFNS meeting to spread the survey. We also like to thank our medical students, Kadir Eryilmaz and Seray Berfin Karagoz, in Antalya and Istanbul respectively for their substantial help to spread our survey in conference meetings hand in hand with our authors.

\section{- REFERENCES}

1. 173 NCG: Neuropathic pain - pharmacological management, in Excellence NlfHaC. Online http://guidance.nice.org.uk/ CG173, 2013 (Updated 2017)

2. Adogwa O, Verla T, Thompson P, Penumaka A, Kudyba $\mathrm{K}$, Johnson $\mathrm{K}$, et al: Affective disorders influence clinical outcomes after revision lumbar surgery in elderly patients with symptomatic adjacent-segment disease, recurrent stenosis, or pseudarthrosis: Clinical article. J Neurosurg Spine 21:153159, 2014

3. Arnold SD, Forman LM, Brigidi BD, Carter KE, Schweitzer HA, Quinn HE, et al: Evaluation and characterization of generalized anxiety and depression in patients with primary brain tumors. Neuro Oncol 10:171-181, 2008

4. Association AP: Diagnostic and Statistical Manual of Mental Disorders (DSM-5). $5^{\text {th }}$ ed. Washington DC: American Psychiatric Association Press, 2013

5. Bot AG, Menendez ME, Neuhaus V, Ring D: The influence of psychiatric comorbidity on perioperative outcomes after shoulder arthroplasty. J Shoulder Elbow Surg 23:519-527, 2014

6. Elsamadicy AA, Adogwa O, Cheng J, Bagley C: Pretreatment of depression before cervical spine surgery improves patients' perception of postoperative health status: A retrospective, single institutional experience. World Neurosurg 87:214-219, 2016

7. Fann JR, Bombardier CH, Richards JS, Wilson CS, Heinemann AW, Warren AM, et al: Venlafaxine extended-release for depression following spinal cord injury: A randomized clinical trial. JAMA Psychiatry 72:247-258, 2015

8. Floyd H, Sanoufa M, Robinson JS: Anxiety's impact on length of stay following lumbar spinal surgery. Perm J 19:58-60, 2015

9. Fox JP, Philip EJ, Gross CP, Desai RA, Killelea B, Desai MM: Associations between mental health and surgical outcomes among women undergoing mastectomy for cancer. Breast $\mathrm{J}$ 19:276-284, 2013

10. Gupta V, Su YS, Wang W, Kardosh A, Liebes LF, Hofman FM, et al: Enhancement of glioblastoma cell killing by combination treatment with temozolomide and tamoxifen or hypericin. Neurosurg Focus 20:E20, 2006
11. Hayashi K, Michiue H, Yamada H, Takata K, Nakayama H, Wei FY, et al: Fluvoxamine, an anti-depressant, inhibits human glioblastoma invasion by disrupting actin polymerization. Sci Rep 6:23372, 2016

12. Hisli N: Beck depresyon envanterinin üniversite öğrencileri için geçerliği, güvenirliği. Psikoloji Dergisi 7(23):3-13, 1989

13. Konno S, Oda N, Ochiai T, Alev L: Randomized, double-blind, placebo-controlled Phase III trial of duloxetine monotherapy in Japanese patients with chronic low back pain. Spine (Phila Pa 1976) 41:1709-1717, 2016

14. Levkovitz Y, Gil-Ad I, Zeldich E, Dayag M, Weizman A: Differential induction of apoptosis by antidepressants in glioma and neuroblastoma cell lines: Evidence for $\mathrm{p}$-c-Jun, cytochrome c, and caspase-3 involvement. J Mol Neurosci 27:29-42, 2005

15. Lishman Organik Psikiyatri Nöropsikiyatri Ders Kitabı, Yagcioglu AE (çev) 4th ed: Wiley-Blackwell, 2013

16. Litofsky NS, Farace E, Anderson F Jr, Meyers CA, Huang W, Laws ER Jr, et al: Depression in patients with high-grade glioma: Results of the glioma outcomes project. Neurosurgery 54:358-366; discussion 366-357, 2004

17. Liu KH, Yang ST, Lin YK, Lin JW, Lee YH, Wang JY, et al: Fluoxetine, an antidepressant, suppresses glioblastoma by evoking AMPAR-mediated calcium-dependent apoptosis. Oncotarget 6:5088-5101, 2015

18. Lopponen P, Tetri S, Juvela S, Huhtakangas J, Saloheimo P, Bode MK, et al: Association between warfarin combined with serotonin-modulating antidepressants and increased case fatality in primary intracerebral hemorrhage: A populationbased study. J Neurosurg 120:1358-1363, 2014

19. Madhusoodanan S, Danan D, Moise D: Psychiatric manifestations of brain tumors: Diagnostic implications. Expert Rev Neurother 7:343-349, 2007

20. Madhusoodanan S, Ting MB, Farah T, Ugur U: Psychiatric aspects of brain tumors: A review. World J Psychiatry 5:273285, 2015

21. Mago R, Mahajan R, Thase ME: Medically serious adverse effects of newer antidepressants. Curr Psychiatry Rep 10:249 257, 2008

22. Mainio A, Hakko $H$, Timonen M, Niemela A, Koivukangas $\mathrm{J}$, Rasanen P: Depression in relation to survival among neurosurgical patients with a primary brain tumor: A 5-year follow-up study. Neurosurgery 56:1234-1241; discussion 1241-1242, 2005

23. Martinez R, Stuhmer W, Martin S, Schell J, Reichmann A, Rohde V, et al: Analysis of the expression of Kv10.1 potassium channel in patients with brain metastases and glioblastoma multiforme: Impact on survival. BMC Cancer 15:839, 2015

24. Menendez ME, Neuhaus V, Bot AG, Ring D, Cha TD: Psychiatric disorders and major spine surgery: Epidemiology and perioperative outcomes. Spine (Phila Pa 1976) 39:E111122, 2014

25. Mercier G, Lennon AM, Renouf B, Dessouroux A, Ramauge $M$, Courtin F, et al: MAP kinase activation by fluoxetine and its relation to gene expression in cultured rat astrocytes. $\mathrm{J}$ Mol Neurosci 24:207-216, 2004 
Bayoumi AB. et al: Antidepressant Prescriptions in Neurosurgery

26. Movig KL, Janssen MW, de Waal Malefijt J, Kabel PJ, Leufkens HG, Egberts AC: Relationship of serotonergic antidepressants and need for blood transfusion in orthopedic surgical patients. Arch Intern Med 163:2354-2358, 2003

27. Polatin PB, Dersh J: Psychotropic medication in chronic spinal disorders. Spine J 4:436-450, 2004

28. Pottegard A, Garcia Rodriguez LA, Rasmussen L, Damkier P, Friis S, Gaist D: Use of tricyclic antidepressants and risk of glioma: A nationwide case-control study. $\mathrm{Br} \mathrm{J}$ Cancer 114:1265-1268, 2016

29. Ramezani S, Vousooghi N, Kapourchali FR, Hadjighasem M, Hayat P, Amini N, et al: Rolipram potentiates bevacizumabinduced cell death in human glioblastoma stem-like cells. Life Sci 173:11-19, 2017

30. Rauma PH, Pasco JA, Berk M, Stuart AL, KoivumaaHonkanen $\mathrm{H}$, Honkanen RJ, et al: The association between major depressive disorder, use of antidepressants and bone mineral density (BMD) in men. J Musculoskelet Neuronal Interact 15:177-185, 2015

31. Renoux C, Vahey S, Dell'Aniello S, Boivin JF: Association of selective serotonin reuptake inhibitors with the risk for spontaneous intracranial hemorrhage. JAMA Neurol 74:173180, 2017

32. Robertson KL, Marshman LA: Gabapentin superadded to a pre-existent regime containing amytriptyline for chronic sciatica. Pain Med 17:2095-2099, 2016
33. Russo-Neustadt A, Ha T, Ramirez R, Kesslak JP: Physical activity-antidepressant treatment combination: Impact on brain-derived neurotrophic factor and behavior in an animal model. Behav Brain Res 120:87-95, 2001

34. Russo-Neustadt AA, Chen MJ: Brain-derived neurotrophic factor and antidepressant activity. Curr Pharm Des 11:14951510, 2005

35. Sajan F, Conte JV, Tamargo RJ, Riley LH, Rock P, Faraday $\mathrm{N}$ : Association of selective serotonin reuptake inhibitors with transfusion in surgical patients. Anesth Analg 123:21-28, 2016

36. Sayadipour A, Mago R, Kepler CK, Chambliss RB, Certa KM, Vaccaro AR, et al: Antidepressants and the risk of abnormal bleeding during spinal surgery: A case-control study. Eur Spine J 21:2070-2078, 2012

37. Şenol M: Psikokutan derma. In: Aydemir Ö, Köroğlu E (eds). Psikiyatride Kullanılan Klinik Ölçekler. Hekimler Yayın Birliği, 2009:93-335

38. Spanova A, Kovaru H, Lisa V, Lukasova E, Rittich B: Estimation of apoptosis in C6 glioma cells treated with antidepressants. Physiol Res 46:161-164, 1997

39. Trouvin AP, Perrot S, Lloret-Linares C: Efficacy of venlafaxine in neuropathic pain: A narrative review of optimized treatment. Clin Ther 39:1104-1122, 2017 